\title{
Patogenicidade do fungo entomopatogênico Beauveria bassiana sobre o percevejo Collaria scenica (Hemiptera: Miridae)
}

\author{
Pathogenicity of entomopathogenic fungus Beauveria bassiana against the \\ grass bug Collaria scenica (Hemiptera: Miridae)
}

\author{
Marcos Roberto Barboza $\left.{ }^{1 *}\right)$ \\ Dener Nascimento Silva ${ }^{2}$ \\ Sebastião Brasil Campos Lustosa ${ }^{3}$ \\ Edson Hirose ${ }^{4}$
}

\section{Resumo}

O percevejo Collaria scenica (Hemiptera: Miridae) é uma praga de cereais cultivados e pastagens, e o controle microbiano é uma alternativa para manter estas populações abaixo do nível de dano econômico. O presente trabalho teve como objetivo avaliar a patogenicidade do isolado CG 460 de Beauveria bassiana sobre este percevejo. Insetos adultos foram inoculados em laboratório com cinco concentrações de

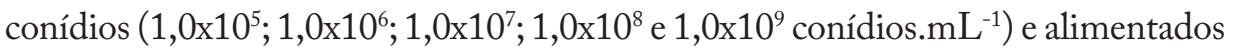
com folhas de trigo. A mortalidade total e confirmada (conidiogênese sobre os insetos mortos) foram avaliadas durante seis dias consecutivos. $\mathrm{O}$ isolado apresentou alta capacidade infectiva sobre o mirideo, com mortalidade total variando de 40 a $90 \%$. A mortalidade confirmada apresentou uma correlação linear positiva com a concentração de conídios. A taxa de conidiogênese nas concentrações mais baixas do inoculo foi em torno de $26 \%$, sendo que nas concentrações maiores os valores chegaram a $70 \%$. O tempo letal 50 para a concentração $10^{9}$ foi de 4,3 dias.

Palavras-chave: controle biológico; percevejo mirideo; Beauveria bassiana; trigo.

I MSc.; Biólogo; Professor do curso de Ciências Biológicas da Faculdade Guairacá. Endereço: Rua XV de novembro, 7050, Centro, CEP:850 10-000, Guarapuava, Paraná, Brasil; E-mail: barbozabio@yahoo.com.br (*) Autor para correspondência.

2 Acadêmico do Curso de Administração da Universidade Estadual do Centro-Oeste, UNICENTRO; Guarapuava, Paraná, Brasil; E-mail: dener.silva@hotmail.com

3 Dr.; Engenheiro Agrônomo; Professor do Departamento de Agronomia da Universidade Estadual do Centro-Oeste, UNICENTRO; Guarapuava, Paraná, Brasil; E-mail: slustosa@unicentro.br

4 Dr.; Engenheiro Agrônomo; Pesquisador A da Embrapa-Soja na Região Centro-Oeste do Brasil e ProfessorOrientador do Programa de Mestrado em Agronomia da Universidade Estadual do Centro-Oeste, UNICENTRO; Guarapuava, Paraná, Brasil; E-mail: edsonhirose@yahoo.com.br

\begin{tabular}{llllll}
\hline Ambiência Guarapuava (PR) & v.7 n.3 & p.473-480 & Set./Dez. 201 I & ISSN I808 - 025I
\end{tabular}




\section{Abstract}

The grass bug, Collaria scenica (Hemiptera: Miridae), is a pest of cereal crops and pastures, and the microbial control is an alternative to maintain the pest population below economic injury level. The present work had the objective to assess the pathogenicity isolate CG460 of Beauveria bassiana against this grass bug. Adult insects had been inoculated in laboratory with five conidia concentrations $(1.0 \times 105$, 1.0x106, 1.0x107, 1.0x108, 1.0x109 conidia.mL-1), and fed with wheat leaves. Total and confirmed mortality (sporulation on the dead insects) had been assessed during six consecutive days. CG460 showed high virulency on the grass bug, with the total mortality ranged from 40 to $90 \%$. Confirmed mortality presented positive and linear correlation with the conidia concentrations. The conidiogenesis rates in the lowest concentrations of inoculum were around $26 \%$, being that in the highest concentrations the values had arrived 70\%. Lethal Time 50 for concentration 109 was 4.3 days.

Key words: biological control; plant bug; Beauveria bassiana; wheat.

\section{Introdução}

Collaria scenica (Hemiptera: Miridae) é um percevejo-praga que tem ganhado destaque na região sul do Brasil atacando várias culturas importantes, como o trigo (SILVA et al., 1994, CARLESSI et al., 1999) arroz, aveia, cevada (GOELLNER; FLOSS, 2001) e pastagens (KALVELAGE, 1988). Na Colômbia C. scenica é responsável por sérios prejuízos em pastagens sendo necessária a intervenção com inseticidas fosforados (MORALES; RODRIGUEZ, 2004). Na região de Guarapuava (PR) o percevejo é encontrado alimentando-se sobre vários hospedeiros anuais e perenes, o que favorece a manutenção de sua população no campo durante todo o ano, dificultando seu controle.

Nestas condições o controle biológico surge como uma alternativa, pois os inseticidas sintéticos, além dos conhecidos danos ambientais, teriam pouca eficiência a campo devido às características da praga relatadas anteriormente. Segundo Alves (1998), no Brasil, a patologia e o controle microbiano de insetos tiveram grande desenvolvimento nos últimos vinte anos, sendo os fungos entomopatogênicos um dos agentes mais promissores para várias pragas agrícolas, entre estes se destaca o fungo Beauveria bassiana (Ascomycota: Hypocreales) um dos mais utilizados em programas de controle biológico, devido à sua eficiência e fácil multiplicação.

Leland et al. (2005) verificaram a possibilidade de utilizar B. bassiana contra hemípteros do gênero Lygus. Ihara et al. (2001) verificaram a patogenicidade de isolados de B. bassiana contra pentatomídeos e relatam bons resultados do fungo como potencial agente de controle biológico.

Para o controle de C. scenica o fungo B. bassiana pode ser uma alternativa ao uso de inseticidas químicos. Assim o presente trabalho teve como objetivo avaliar a virulência do isolado CG460 do fungo B. bassiana sobre o mirídeo C. scenica em 
laboratório, servindo como referência para estudos posteriores de controle biológico desta praga a campo.

\section{Material e Métodos}

O trabalho foi desenvolvido no Laboratório de Entomologia Agrícola da Universidade Estadual do Centro-Oeste, UNICENTRO, em sala climatizada $(25 \pm 2$ ${ }^{\circ} \mathrm{C}, 60 \pm 10 \% \mathrm{UR}$, fotoperíodo $14 \mathrm{~h} \mathrm{~L}: 10 \mathrm{~h} \mathrm{E}$ ). Os insetos utilizados nos bioensaios foram coletados no campo experimental do Campus CEDETEG em plantas de papuã (Brachiaria plantaginea) e aveia branca (Avena strigosa). A coleta ocorreu $24 \mathrm{~h}$ antes da realização dos bioensaios e os insetos foram mantidos em sala climatizada e alimentados com folhas de trigo até a inoculação do fungo.

O isolado CG460 de B. bassiana foi utilizado devido à sua facilidade de obtenção e testado por não existirem trabalhos com este isolado sobre o mirideo C. scenica. Esta cepa foi obtida junto à Embrapa soja em Londrina-PR, e mantido em meio de cultura BDA (batata, dextrose e ágar) em placas de Petri até a realização dos bioensaios. Em laboratório o isolado foi repicado em frascos de vidro $(200 \mathrm{ml})$ contendo arroz pré-cozido e autoclavado, seguindo metodologia descrita por Alves et. al. (1998). Os conídios foram suspensos em água destilada e autoclavada e a concentração foi determinada com auxilio de câmara Newbauer. Foram utilizadas as seguintes concentrações: $1,0 \times 10^{5} ; 1,0 \times 10^{6}$; $1,0 \times 10^{7} ; 1,0 \times 10^{8}$ e $1,0 \times 10^{9}$ conídios. $\mathrm{mL}^{-1}$ e a viabilidade dos conídios foi superior a $95 \%$.

Os bioensaios foram delineados em esquema inteiramente casualizado, com cinco repetições, nas cinco concentrações, mais a testemunha. Cada repetição consistiu de um recipiente plástico descartável de $300 \mathrm{~mL}$, com tampa transparente. Em cada recipiente foi colocado, no fundo, papel filtro tratado com $0,5 \mathrm{~mL}$ de suspensão de conídios e para a testemunha, $0,5 \mathrm{~mL}$ de água destilada. Foram colocados seis insetos adultos (machos e fêmeas), por recipiente, os quais foram selecionados entre os mais ativos e saudáveis da criação. A inoculação dos insetos deu-se através do contato com a superfície tratada, pois estes ficaram sobre o papel tratado por todo o período dos bioensaios. Para a alimentação dos insetos foram utilizadas folhas de trigo (cultivar Ônix) provenientes de plantas com 15 a 20 dias de emergência, mantidas em vasos. As folhas foram colhidas, lavadas com água destilada e colocadas dentro do recipiente sobre o papel filtro, o alimento foi trocado diariamente.

As avaliações foram feitas a cada 24 $\mathrm{h}$, por seis dias consecutivos, retirando-se, se de cada recipiente, os insetos mortos, que eram transferidos para novos recipientes de plástico descartável $(150 \mathrm{~mL})$ forrados com papel filtro umedecido com água destilada para a confirmação da mortalidade pelo fungo. Os dados de mortalidade (total e confirmada) das concentrações testadas e o tempo letal na concentração $10^{9}$ conidios. $\mathrm{mL}^{-1}$ foram submetidos à análise de regressão linear e polinomial. A taxa de conidiogênese (número de insetos com esporulação/total de insetos mortos) foi submetida os teste de $\chi 2$ (>95\%).

\section{Resultados e Discussão}

O isolado CG460 de B. bassiana apresentou boa capacidade infectiva sobre C. scenica. $\mathrm{Na}$ Figura 1 observa-se que a mortalidade total não variou entre as concentrações $10^{5}$ até $10^{8}$ conídios. $\mathrm{mL}^{-1}$, permanecendo em torno de $40 \%$. Neves 


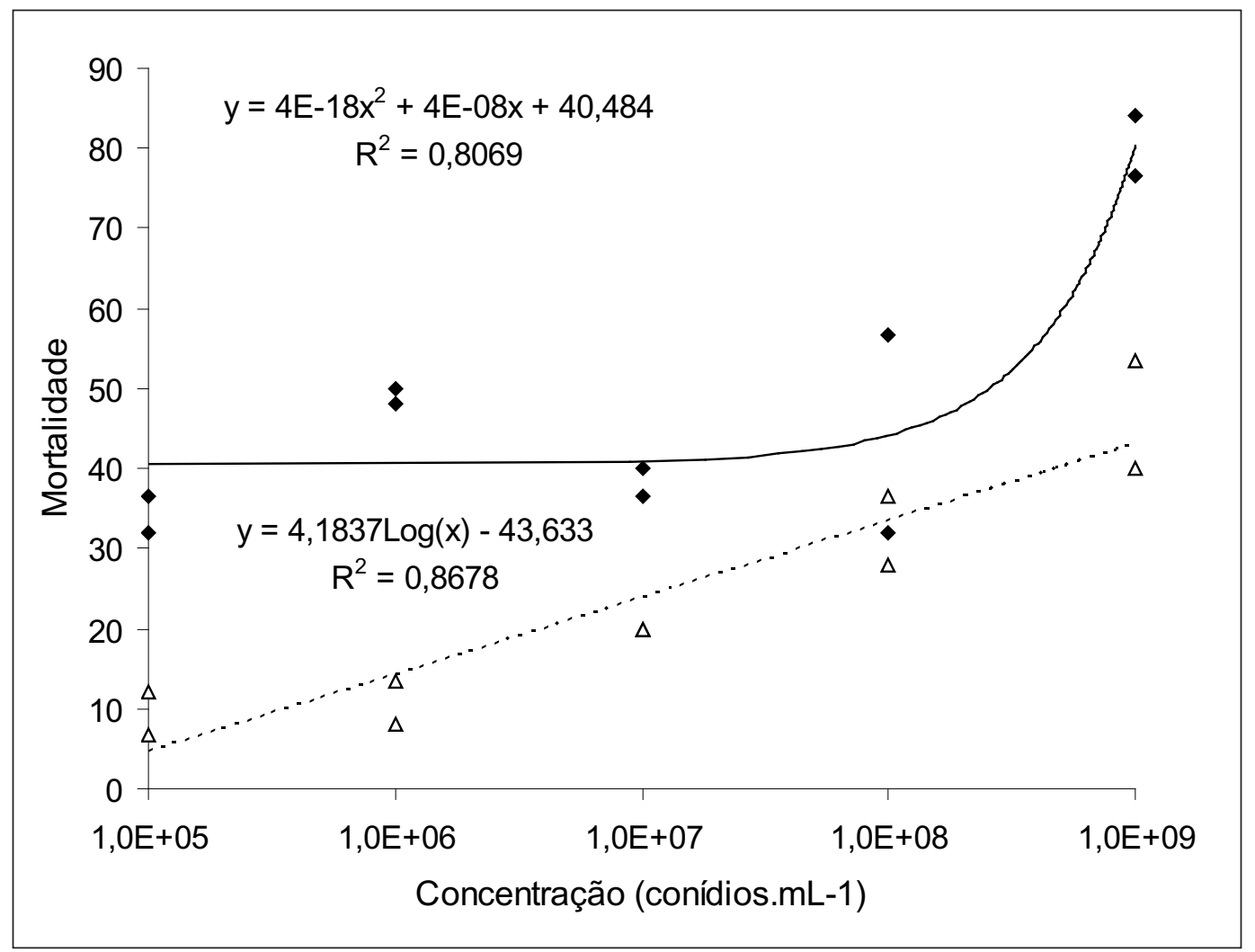

Figura I. Curva da mortalidade total (-) e confirmada (---) de Collaria scenica submetidos a diferentes concentrações de Beauveria bassiana - CG 460

\& Hirose (2005) observaram taxas de mortalidade acima de 60\%, utilizando o isolado CG432 de B. bassiana sobre Hypothenemus hampei (Coleoptera: Scolytidae). É provável que a não variação da mortalidade nestas concentrações se deva à metodologia de bioensaio, uma vez que os conídios foram distribuídos no papel filtro e isto pode ter restringido o contato dos esporos com os insetos.

Segundo Alves (1998) o conídio necessita atravessar a cutícula e invadir a hemocele. Após a invasão o fungo pode causar a morte do hospedeiro de forma indireta, pela exaustão de nutrientes e digestão dos tecidos internos, e/ou de forma direta pela liberação de metabólicos secundários (toxinas), pelo patógeno (HAJEK; St. LEGER, 1994). Em muitos casos ocorre a combinação destes fatores (FERRON, 1978; HAJEK e St. LEGER, 1994). Quando a morte ocorre por fatores diretos, nem sempre há condição do fungo se desenvolver no corpo do inseto, que pode ser tomado por septicemia devido à redução da capacidade de resistência (HAJEK e St. LEGER, 1994; CHARNLEY,1997). Assim mesmo o menor contato com os conídios pode ter contribuído como um fator de estresse que causou a morte dos insetos testados.

A mortalidade confirmada variou de $8 \%$ a $50 \%$ e apresentou uma correlação linear positiva com a concentração de conídios, com um bom ajuste dos dados $\left(R^{2}=0,86\right)$, o que 
comprova a ação letal do fungo (Figura 1). Segundo Alves (1998), agentes microbianos necessitam de maior tempo de exposição e desenvolvimento para causarem mortalidade, e em alguns casos torna-se difícil atribuir a causa de morte. No caso dos fungos entomopatogênicos a forma de comprovar o real efeito do fungo é esperar a conidiogênese sobre o inseto morto.

Para o isolado CG 460 a taxa de conidiogênese nas concentrações $10^{5}$ e $10^{6}$ foi em torno de $26 \%$, significativamente inferior às concentrações maiores $\left(10^{7} \mathrm{a}\right.$ $\left.10^{9}\right)$, que chegou a $70 \%$ nestas concentrações (Figura 2). Entre as concentrações $10^{8}$ e $10^{9}$ não houve diferença significativa na taxa de conidiogênese. A capacidade de produção de conídios sobre os cadáveres é um importante fator a se considerar, uma vez que estes são as fontes de inoculo para a propagação da doença na área (NEVES; HIROSE, 2005). Sosa-Gómez e Alves (2000), mostraram que diferenças na produção de conídios em cadáveres de percevejos, são dependentes de condições abióticas como temperatura e umidade relativa, além das diferenças entre os isolados de B. bassiana.

A virulência $B$. bassiana sobre $C$. scenica é clara, pois a mortalidade foi acima de $80 \%$ na concentração maior de conídios $\left(10^{9}\right)$, isto se deve provavelmente a maior facilidade de contato do inseto com os conídios pela maior concentração. Contudo, alta conidiogênese e potencial epizoótico podem ter igual ou maior importância em um programa de controle biológico (CHARNNEY, 1997). A dispersão dos propágulos infectivos viáveis (conídios) para um novo hospedeiro representa a parte mais delicada do ciclo de vida do fungo, devido à ação de agentes

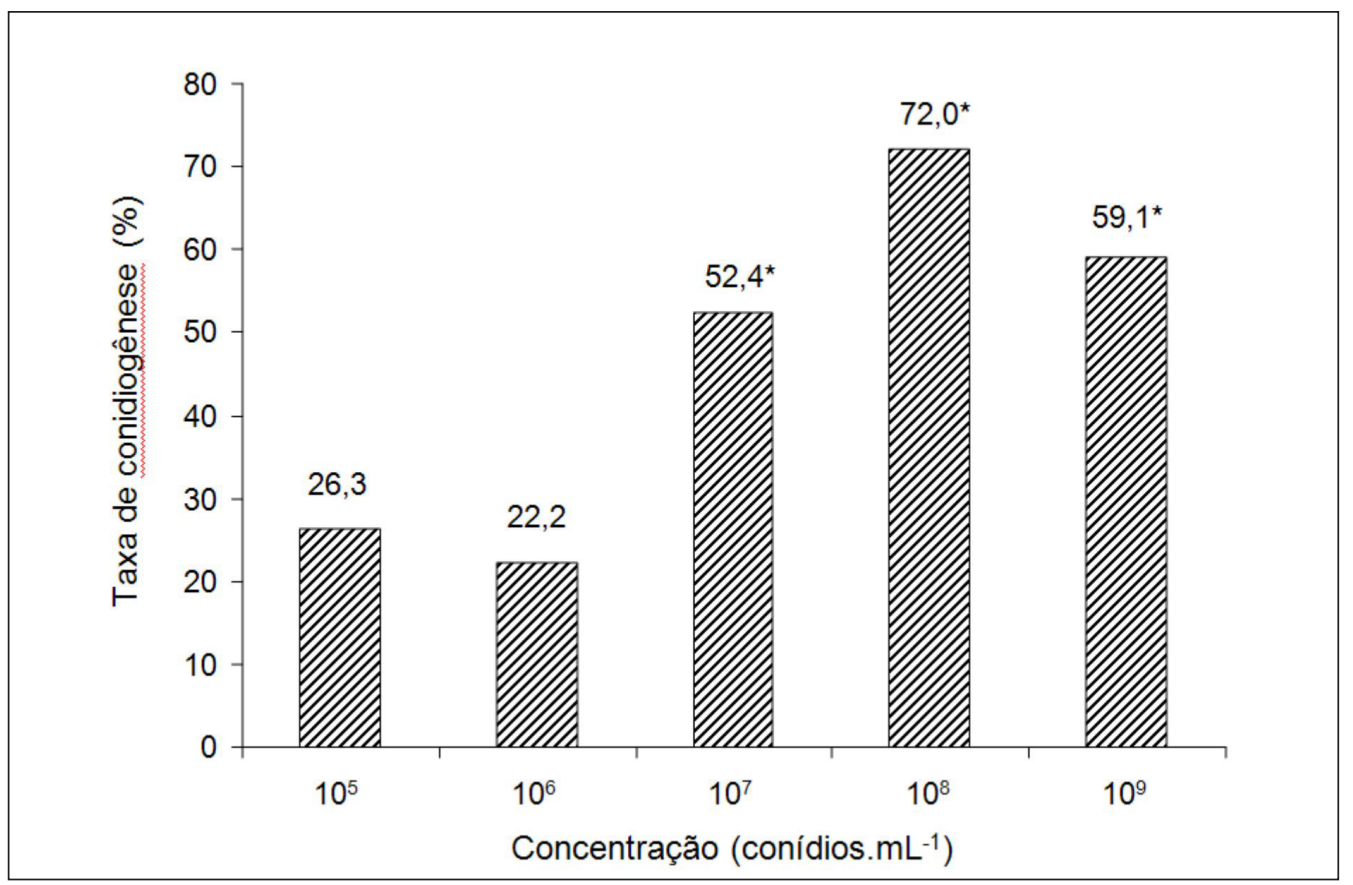

Figura 2. Taxa de conidiogênese (mortalidade confirmada/mortalidade total) em Collaria scenica submetidos a diferentes concentrações do isolado CG 460 de Beauveria bassiana. Presença de $(*)$ indica diferença significativa entre as concentrações pelo teste de $\chi^{2}$ ( > 95\%) 
desativadores, principalmente a temperatura, a umidade e a radiação, que afetam também o processo da produção de conídios, dispersão, sobrevivência e germinação. Assim, maior número de conídios produzidos, compensaria parcialmente a elevada probabilidade da maioria não sobreviver para infectar um novo hospedeiro (HAJEK; St. LEGER, 1994).

Outro fator a se considerar é a velocidade que um determinado agente de controle é capaz de atuar sobre seu alvo. Neste experimento o tempo letal $50\left(\mathrm{TL}_{50}\right)$ na concentração $10^{9}$ foi de 4,3 dias (Figura 3).

Leland et al. (2005) testando vários isolados de $B$. bassiana para duas espécies do gênero Lygus (Hemiptera: Miridae) encontraram valores de $\mathrm{TL}_{50}$ variando de 4,3 a 15 dias, dependendo do inseto e do isolado de $B$. bassiana, sendo que em média os valores foram de seis dias. Mesmo sendo as espécies e a metodologia de bioensaio utilizados por Leland et al. (2005) diferentes, os valores de $\mathrm{TL}_{50}$ servem para ilustrar a necessidade do tempo, normalmente dias, para que o fungo cause mortalidade, e que este tempo pode variar de acordo com o isolado. Os valores obtidos por Leland et al. (2005) foram próximos aos obtidos neste experimento, o que demonstra a possibilidade da utilização deste fungo como um agente de controle biológico para percevejos desta família.

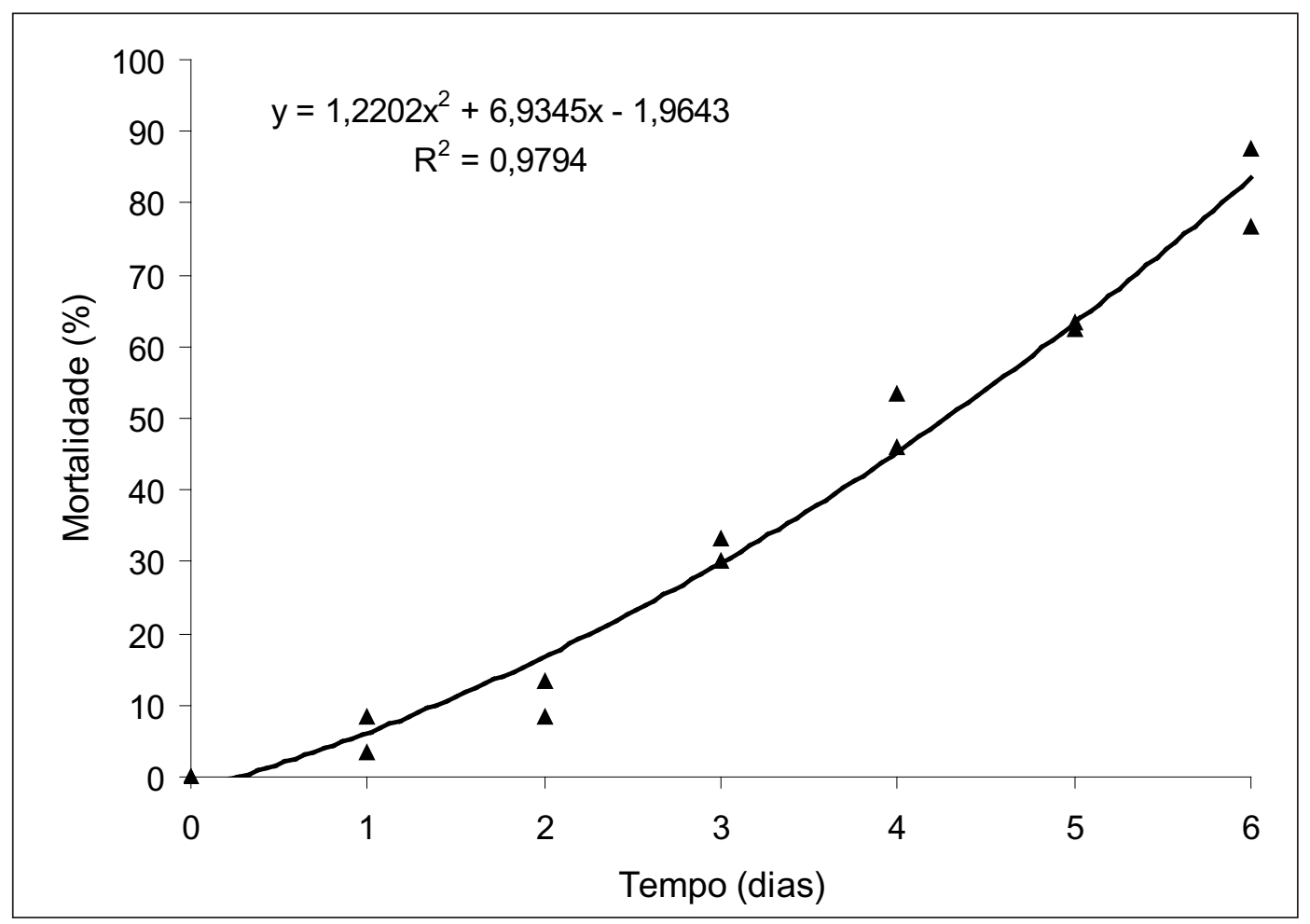

Figura 3. Curva de tempo letal de Collaria scenica submetido à concentração de $10^{9}$ conídios. $\mathrm{mL}^{-1}$ do isolado CG 460 de Beauveria bassiana 


\section{Considerações Finais}

Comprovada a possibilidade de B. bassiana causar mortalidade em $C$. scenica, há a necessidade de testar outros isolados de B. bassiana, e isolados de outras espécies de fungos entomopatogênicos como Metharhizium anisopliae, além de outras metodologias de bioensaios para se verificar o agente de controle mais promissor, além de testar sua adequação em condições de campo, frente aos agentes desativadores.

\section{Agradecimentos}

A CAPES pela bolsa de mestrado concedida ao primeiro autor e aos estagiários do laboratório de Entomologia do Departamento de Agronomia UNICENTRO Marcelo Bridi e Jefferson Rocha.

\section{Referências}

ALVES, S. B. Fungos entomopatogênicos. In: ALVES, S. B. (Org.). Controle microbiano de insetos: São Paulo: FEALQ2 1998. p. 289-381.

CARLESSI, L. R. G.; CORSEUIL, E.; SALVADORI, J. R. Aspectos Biológicos e Morfométricos de Collaria scenica (Stal) (Hemiptera: Miridae) em Trigo.Anais da Sociedade Entomológica Brasileira, Londrina, v. 28, n.1, p.65-73,1999.

CHARNLEY, A. K. Entomopathogenic fungi and their role in pest control.In:WICKLOW, D. T.; SÖDERSTRÖM, B. (Eds.). Environmental and microbial relationships. The Micota IV. Heidelberg: Springer-Verlag, 1997. p. 185-218.

FERRON, P. Biological Control of insect pests by entomogenous fungi. Annual Rewiew of Entomology, Palo Alto, v. 23, n.1, p. 409-442, 1978.

GOELLNER, C. I.; FLOSS, E. L. Insetos - pragas da cultura da aveia: Biologia controle e manejo. Passo Fundo: UPF, 2001. 96 p.

HAJEK, A. E.; ST. LEGER, R. J. Interactions between fungal pathogens and inset hosts. Annual Review Entomology, Palo Alto, v. 39, n.1, p. 293-322, 1994.

IHARA, F.; YAGINUMA, K.; KOBAYASHI, N.; MISHIRO, K.; SATO, T. Screening of entomopathogenic fungi against the brown-winged green bug, Plautia stali Scott (Hemiptera: Pentatomidae). Japonese Journal of Applied Entomology and Zoology, Tokyo, v. 36, [S.I.], p. 495-500, 2001.

KALVELAGE, H. Collaria scenica (Stal, 1859) (Hemiptera: Miridae): praga de gramineas forrageiras na região do planalto catarinense, Brasil. Anais da Sociedade Entomológica Brasileira, Itabuna, v.17, n.1, p. 221-222, 1988. 
LELAND, J. E.; MCGUIRE, M. R.; GRACE, J. A.; JARONSKI, S. T.; ULLOA, M.; PARK, Y. H.; PLATTNER, R, D. Strain selection of a fungal entomopathogen, Beauveria bassiana for control of plant bugs (Lygus spp.) (Heteroptera: Miridae). Biological Control, v. 35, n.2, p. $104-114,2005$.

MORALES, C. A.; RODRIGUEZ, N. El cloropirifos; possible disruptor endócrino em bovinos de leche. Revista Colombiana de Ciências Pecuárias, Medellín, v. 17, n. 3, p. 255$267,2004$.

NEVES, P. M. O. J.; HIROSE, E. Seleção de isolados de Beauveria bassiana para o controle biológico da broca-do-café Hypothenemus hampei (Ferrari) (Coleoptera: Scolytidae). Neotropical Entomology, Londrina, v. 34, n. 1, p. 77-82, 2005.

SILVA, D. B.; ALVES R. T.; FERREIRA, P. S. F.; CAMARGO, A. J. A. Collaria oleosa (Distant, 1883) (Heteroptera: Miridae), uma praga potencial na cultura do trigo na região dos cerrados. Pesquisa Agropecuária Brasileira, Brasília, v. 29, n. 12, p. 2007-2012, 1994.

SOSA-GÓMEZ, D. R.; ALVES, S.B. Temperature and relative humidity for conidiogenesis of Beauveria bassiana (Deuteromycetes: Moniliaceae). Anais da Sociedade Entomológica Brasileira, Londrina, v. 29, n.3, p. 515-521, 2000. 